\title{
DISORDERS OF TEMPERATURE REGULATION IN ACUTE TRAUMATIC TETRAPLEGIA
}

\author{
H. G. Pledger, Liver Pool, England
}

From the Royal Victoria Infirmary, Newcastle-upon-Tyne

Recent clinical accounts of patients with acute traumatic tetraplegia have said little about temperature disorders, although some authors have referred to hyperpyrexia and have attributed it to ascending oedema or haemorrhage in the spinal cord (Ellis 1946), broncho-pneumonia (Durbin 1957), or various infections (Comarr 1958). Some text-books (Birkett 1950, WatsonJones 1955, McLaughlin 1959, Cooper and Ross 1960) and editorial reviews (White 1959) make no mention of temperature control in this condition. Spontaneous hypothermia has not been mentioned in these recent reports, although earlier authors have reported both this and hyperpyrexia (Pembrey 1898, Gardiner and Pembrey 1912, Holmes 1915): the first record of hypothermia was in 1874 (Hutchinson 1875). That the temperature of a tetraplegic patient should have a tendency to respond to environmental temperature in the same way as a coldblooded animal was postulated as the cause of this condition by Pembrey (1897) and later by others (Erickson 1939; Pollock, Boshes, Choc, Finkelman, Arieff and Brown 1951), and was shown to occur in tetraplegic animals by Sherrington (1924) and in men with chronic tetraplegia by Tigay (1956) and Guttmann, Silver and Wyndham (1958). Recent experience at this hospital suggests that considerable alteration of the body temperature may be a common feature of acute traumatic tetraplegia.

\section{CASE REPORT}

A man aged thirty had an accident on a motor scooter. He was admitted to another hospital where he was found to have a tetraplegia from the level of the sixth cervical segment, with fractures of the fifth and sixth cervical vertebrae and backward displacement of part of the fifth. He also had a fracture of the shaft of the right femur, but he had not been unconscious and there was no evidence of injury to brain or skull. Seven hours later, after treatment for the initial shock, he was transferred to this hospital. Respiration was diaphragmatic and his vital capacity was 1,200 millilitres, but there was no respiratory distress. His temperature was 36.2 degrees Centigrade (97.0 degrees Fahrenheit) and his pulse rate was 90 per minute. There was some shivering of the facial muscles. In addition to the motor and sensory loss from the level of the sixth cervical segment it was noticed later that he had a bilateral Horner's syndrome, nasal congestion (Guttmann's sign) and absence of sweating. Blackburn's skull traction apparatus was applied under local anaesthesia and he was nursed on a Stryker frame.

On the next day the vital capacity was 1,600 millilitres, the temperature $36 \cdot 2$ degrees Centigrade (97.0 degrees Fahrenheit), and the pulse rate slowed during the day from 80 to 65 per minute.

The following day he was confused and uncooperative, and in the evening his pulse was only 40 per minute; although the temperature had been recorded as $36 \cdot 2$ degrees Centigrade ( 97.0 degrees Fahrenheit) earlier in the day, he felt cold to the touch. The rectal temperature was taken, at first with a mercury thermometer which failed to register, and then with a thermocouple which gave a reading of 30.8 degrees Centigrade ( 87.4 degrees Fahrenheit). An electrocardiograph showed sinus bradycardia, delayed conduction and $\mathbf{J}$ waves, all characteristic of hypothermia. As ventricular fibrillation may occur below 29.0 degrees Centigrade ( 84.2 degrees Fahrenheit) the patient was warmed with an electric blanket to 35.0 degrees Centigrade (95.0 degrees Fahrenheit). During the next three days his temperature 
gradually rose to 37.0 degrees Centigrade (98.6 degrees Fahrenheit) and the pulse rate increased to 72 per minute (Fig. 1).

The vital capacity was measured again as soon as the patient could cooperate and had increased to 2,100 millilitres. Subsequently, apart from a few short feverish episodes, he was kept at a near-normal temperature by varying the amount of covering. He was discharged to a rehabilitation unit ten weeks after the accident with no evidence of recovery of the tetraplegia.

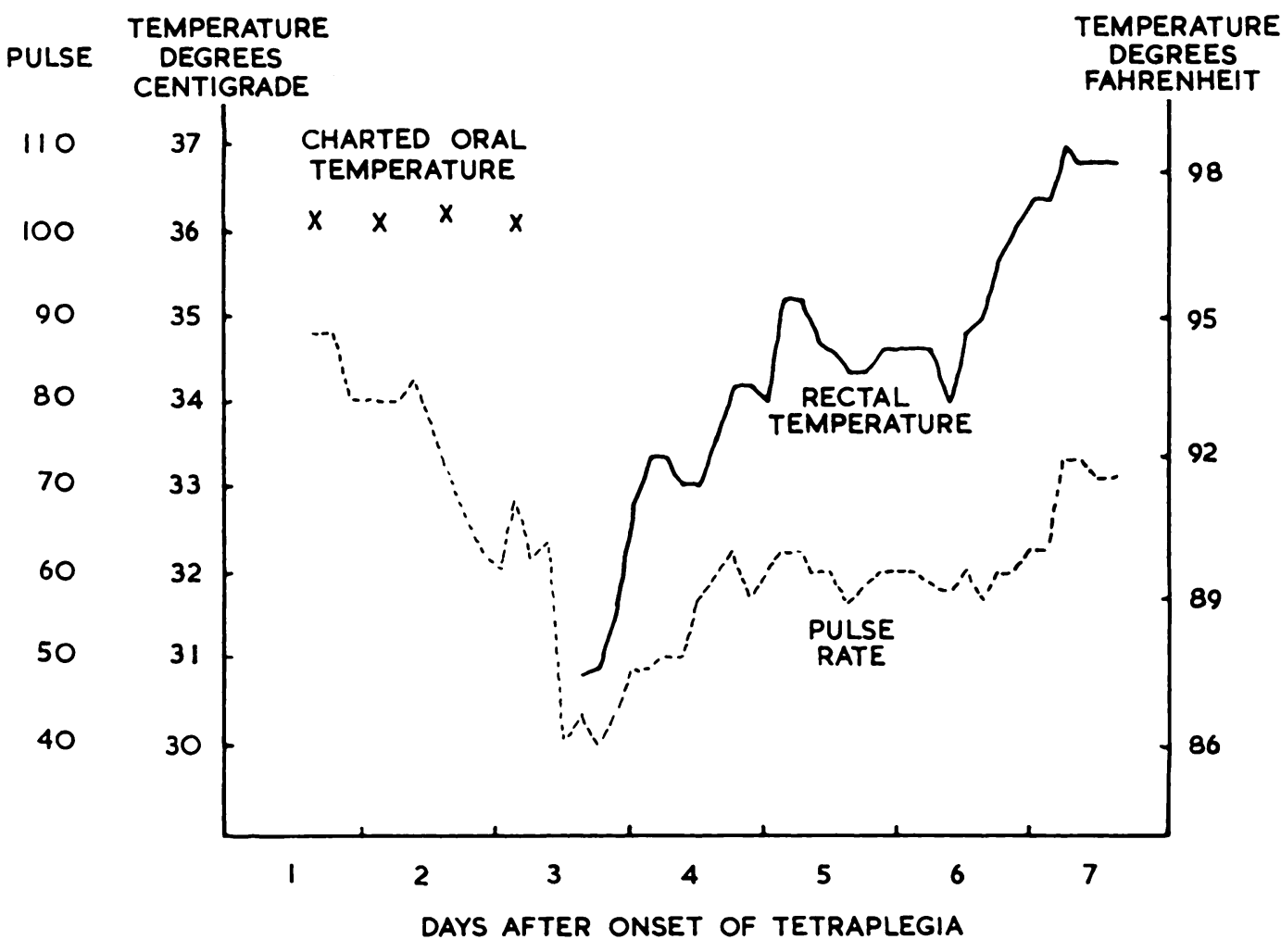

Fig. 1

Case 1-The pulse and temperature chart for the first week.

This finding of spontaneous hypothermia prompted a perusal of the records of seven other patients with acute traumatic tetraplegia admitted during the last eight years, of whom the temperature charts of six were found. Four of these had temperatures of $36 \cdot 2$ degrees Centigrade (97.0 degrees Fahrenheit) or below, with pulse rates of 50 per minute or less, during their first three days in hospital. Hyperpyrexia occurred in three patients just before death and it is of interest that these patients were admitted during the summer months. Necropsy was done on five patients and all showed damage to the spinal cord but no evidence of damage to brain-stem or medulla.

\section{DISCUSSION}

Functional section of the spinal cord above the first thoracic segment prevents the action of the effector mechanism of temperature control in two ways in particular. First, by damaging the connections between the temperature regulating centre in the hypothalamus and the sympathetic outflow from the cord, vasoconstriction and sweating are prevented and vasodilation occurs, as it does after surgical sympathectomy. Secondly, damage to the motor 
tracts prevents shivering except in the non-paralysed muscles. A tetraplegic patient is thus an imperfect homeotherm and cannot maintain normal body temperature in extremes of temperatures.

This almost complete destruction of the compensatory mechanism of temperature control is enough to explain the rise or fall of body temperature seen in these patients. Before admission patients may be exposed to low temperatures, and during the radiological and clinical examination and general nursing care may lie uncovered for long periods. The temperatures of the surroundings may be raised in summer, especially in small side wards, or external heat may be applied. That most tetraplegic patients in India are feverish on admission to hospital (Comarr 1958) can be explained by this hypothesis. An additional factor in the loss of temperature control is that a vicious circle is established by a raised environmental temperature which raises the body temperature, which increases the metabolic rate; this in turn gives an increased endogenous heat production which, with an inability to increase heat loss significantly, leads to a further rise in body temperature. The reverse process applies when the temperature of the environment is lowered.

There is little evidence to support the theory that oedema or haemorrhage in the cord spreads upwards to the temperature regulating centre in the hypothalmus thus to affect body temperature. It is extremely unlikely that this could occur without interference to the respiratory or vaso-motor centres in the medulla; also in this small series there was no pathological evidence of any intracranial lesion. The patient described here had an increasing vital capacity at the time that he became hypothermic, suggesting that there was no upward extension of the cord lesion. Infections such as bronchopneumonia do not usually cause hyperpyrexia in adults, especially within twenty-four hours of injury as may sometimes occur. Early bronchopneumonia was found in this series at only one out of five necropsies.

\section{CONCLUSIONS}

The body temperature of patients with acute traumatic tetraplegia is in the control of the medical and nursing staff, because the cord lesion deprives the patient of almost all the means of compensating for changes in his environmental temperatures. Management of such patients should include avoidance of excessive cold or heat, and frequent oral temperature readings should be taken. If the temperature falls below $36 \cdot 2$ degrees Centigrade ( 97.0 degrees Fahrenheit) the rectal temperature should be taken. Failure to shake mercury thermometers down completely before use may lead to failure to notice the onset of hypothermia. Active cooling or warming should be used to keep body temperature near normal. Fever may or may not be a sign of infection, and this must be decided on clinical and bacteriological methods.

\section{SUMMARY}

1. A patient is described who developed hypothermia shortly after being rendered tetraplegic by a fracture of the cervical spine.

2. The causes and prevention of hypothermia or hyperpyrexia in tetraplegia are discussed.

I should like to thank Mr J. K. Stanger for permission to publish details of the patient who was admitted under his care, and Professor E. A. Pask, Mr P. N. Robson, Dr E. A. Cooper and Mr J. C. Wardill for their helpful criticism and advice.

\section{REFERENCES}

Birkett, A. N. (1950): In Modern Trends in Orthopaedics. Edited by Sir H. Platt. (First Series), p. 301. London: Butterworth \& Co. (Publishers) Ltd.

Comarr, A. E. (1958): Differential Diagnosis of High Fevers Peculiar to Spinal Cord Injury Patients. Journal of the Indian Medical Profession, 5, 2,223.

CoOper, K. E., and Ross, D. N. (1960): Hypothermia in Surgical Practice, p. 94. London: Cassell. 
Durbin, F. C. (1957): Fracture-Dislocations of the Cervical Spine. Journal of Bone and Joint Surgery, 39-B, 23.

Ellis, V. H. (1946): Injuries of the Cervical Vertebrae. Proceedings of the Royal Society of Medicine (Section of Orthopaedics), 40, 21.

ERICKSON, T. C. (1939): Neurogenic Hyperthermia. Brain, 62, 172.

Gardiner, H., and Pembrey, M. S. (1912): Observations on the Temperature of Man after Traumatic Section of the Spinal Cord. Guy's Hospital Reports, 66, 87.

Guttmann, L., Silver, J., and Wyndham, C. H. (1958): Thermoregulation in Spinal Man. Journal of Physiolog.", 142, 406.

Holmes, G. (1915): Spinal Injuries of Warfare. British Medical Journal, ii, 818.

Hutchinson, J. (1875): Clinical Lecture on the Temperature and Circulation after Crushing of the Cervical Spinal Cord. Lancet, i, 715.

McLaughlin, H. L. (1959): Trauma, p. 598. Philadelphia and London: W. B. Saunders Company.

Pembrey, M. S. (1897): The Temperature of Man and Animals after Section of the Spinal Cord. British Medical Journal, ii, 883.

Pembrey, M. S. (1898): In Text-Book of Physiology. Edited by E. A. Schafer. Volume I, p. 860. London: Young J. Pentland.

Pollock, L. J., Boshes, B., Choc, H., Finkelman, I., Arieff, A. J., and Brown, M. (1951): Defects in Regulatory Mechanisms of Autonomic Function in Injuries to Spinal Cord. Journal of Neurophysiolog., 14, 85.

Sherrington, C. S. (1924): Notes on Temperature After Spinal Transection, with some Observations on Shivering. Journal of Physiology, 58, 405.

Tigay, E. L. (1956): Dysregulation of Temperature Control in Cervical Spinal Cord Lesions. In Proceedings of Fifth Annual Paraplegia Conference, p. 80. Veterans' Administration Hospital, Hines, Illinois.

Watson-Jones, Sir R. (1955): Fractures and Joint Injuries. Fourth edition, p. 984. Edinburgh and London: E. \& S. Livingstone Ltd.

White, J. C. (1959): Injuries to the Cervical Cord. Journal of Bone and Joint Surgery, 41-A, 11. 